\title{
LA CONSTITUCIÓN POLÍTICA DE LOS ESTADOS UNIDOS MEXICANOS. UN BREVE RECORRIDO POR SUS REFORMAS, CON ESPECIAL ENFOQUE EN EL SISTEMA PENAL
}

\author{
The Political Constitution of the United Mexican States. \\ A brief tour for his reforms, with special approach in the penal system
}

Luis Felipe GUERRERO AGRIPINO*

Sumario:

I. Introducción II. El basamento III. Situación actual IV. Consistencia técnica-estructural V. Algunas reformas VI. Conclusiones VII. Última consideración VIII. Bibliografía

Resumen: A cien años de la promulgación de la Constitución Política de los Estados Unidos Mexicanos, se presenta una síntesis sobre la transformación de la Carta Magna a lo largo de un siglo, lo cual se aborda a partir de los siguientes ejes estructurales, que a su vez, representan una visión sobre la evolución del Estado Mexicano: reformas que inciden en los basamentos revolucionarios, reformas a la estructura del poder público y de sus instituciones, rectoría del Estado en la economía y el desarrollo nacional, en materia de derechos humanos, anticorrupción y transparencia $y$, finalmente, la que corresponde al sistema de justicia penal.

Palabras clave: Constitución, reforma constitucional, basamentos revolucionarios, poder público, derechos humanos, sistema penal.

Abstrac: A century after the promulgation of the Political Constitution of the United Mexican States, a synthesis is presented on the transformation of the Constitution over a century, which is addressed from the following structural axes, which in turn, represent a vision on the evolution of the Mexican State: reforms that affect the revolutionary foundations, reforms to the structure of public power and its institutions, stewardship of the State in the economy and national development, in the area of human rights, anti-corruption and transparency and, finally, that which corresponds to the criminal justice system.

Key words: Constitution, constitutional reform, public power, human rights, penal system.

\section{Introducción}

En el año 2017 la Constitución Política de los Estados Unidos Mexicanos (en adelante CPEUM) cumplió cien años de su promulgación. Esta conmemoración dio lugar a que en nuestro País

\footnotetext{
Doctor en Derecho por la Universidad de Salamanca, España. Profesor titular del Departamento de Derecho de la División de Derecho, Política y Gobierno del Campus Guanajuato de la Universidad de Guanajuato, México. Miembro del Sistema Nacional de Investigadores. Rector General de la Universidad de Guanajuato, México.
} 
se desarrollarán una serie de eventos académicos, políticos y culturales. También, fue motivo para que proyectos y programas de diversa índole destinaran en sus contenidos un espacio para hacer o decir algo sobre el referido acontecimiento.

Bajo esta última modalidad se hizo lo propio en el Festival Internacional Cervantino (FIC). Este festival tiene 46 años de existencia y, anualmente, convierte a la ciudad de Guanajuato en el espacio propicio para la presentación de diversas creaciones artísticas, la música, el baile, las artes escénicas, la memoria, las artes visuales y el diálogo cultural.

En el marco de dicho Festival, en su edición 45, se incorporaron diversas actividades para rendir homenaje a la CPEUM. Una de ellas fue la impartición de la conferencia La Constitución de 1917 y sus reformas, con especial enfoque en el sistema penal, la cual se me encomendó.

Derivado de esa intervención, me di a la tarea de configurar lo pronunciado ante el público en un texto con mayor sistematización y sustento, con la pretensión de compartirlo ahora con un público lector.

Cuando el entonces Director del FIC, el destacado escritor mexicano Jorge Volpi, me pidió que impartiera una conferencia en el marco del Festival, de inmediato sentí extrañeza, no lograba visualizar un nivel de involucramiento en la programación más allá de los actos de orden protocolario. No obstante, al aclararme que el tema sería sobre la conmemoración de los cien años de la Promulgación de la Constitución Mexicana y a partir del eje temático revoluciones, me pareció interesante.

Obviamente, asumir un análisis de tal magnitud implicó sentar previamente algunas bases y advertencias. El estudio puede enfocarse desde diferentes disciplinas: la historia, la política, la sociología, le economía, la jurídica, entre otras. Y desde el enfoque jurídico cabe una gran diversidad de delimitaciones.

Debido a mi formación académica, la intervención estuvo orientada desde una perspectiva fundamentalmente de índole jurídico. No obstante, se trató, a su vez, de establecer un panorama de carácter general de la Constitución y hacer una especial referencia al sistema penal y de seguridad pública.

\section{El basamento}

Primeramente, es importante precisar que toda Constitución es un instrumento político, jurídico; ideológico, histórico. En ese sentido, no es posible entender la Constitución de un País sin conocer su historia, el contexto bajo el cual surgió, se inspiró; lo que prevalecía en el medio nacional al momento de su elaboración y los caminos que se tuvieron que recorrer para llegar a la formulación de dicho documento.

En el caso que nos ocupa, es importante ubicarnos, primeramente, en las Constituciones antecesoras de la actual. En México hemos tenido seis cartas fundamentales, incluyendo la vigente: la de 1814 (surgida en plena guerra de independencia, conocida como la Constitución de Apatzingán), la de 1824, la de 1836, la de 1843 , la de 1857 y la de $1917^{1}$.

Entre la primera y la vigente es de destacar lo siguiente: cuando México logró su independencia, su principal referente fue Francia, lugar en el que se transformaba al mundo occidental por los ideales revolucionarios y posrevolucionarios: la libertad, la igualdad, la fraternidad. Sobre

1 Ver, Fernández Ruiz, Jorge (2013), “El constitucionalismo en el primer siglo del México independiente”, en: Constitucionalismo, dos siglos de su nacimiento en América Latina, César Astudillo y Jorge Carpizo (Coords.), UNAM, México. 
todo, cobraba forma el sustento del contrato social: los gobernados ceden el poder al Estado y éste garantiza su seguridad y lo hace de manera limitada. Otro referente que no podemos soslayar es la influencia del sistema constitucional norteamericano, más que por la cercanía geográfica, por los fundamentos libertarios de la Constitución de Filadelfia.

Ahora bien, es importante ubicarnos en la Constitución antecesora a la vigente, la de 1857. Estamos hablando de un cierre del ciclo de las constituciones del siglo XIX. Fue una Constitución de un corte profundamente liberal: no hizo una declaración de laicidad, pero suprimió el precepto conforme al cual todas las constituciones precias habían establecido que la religión católica era obligatoria.

En estricto sentido, la Constitución de 1857 culminó el proceso de independencia y la construcción del Estado mexicano. A diferencia de las otras, sí permitía su modificación, lo cual sirvió a Porfirio Díaz para legitimar su dictadura.

Así, nos ubicamos en 1917. Existía un México independiente, pero ¿cuál era el peso histórico que cargábamos y cuál era la situación prevaleciente en ese tiempo? Traíamos el resentimiento histórico de las intervenciones extranjeras y el desgaste derivado de guerras civiles. Traíamos el peso reciente de una dictadura de treinta años. Sin dejar de lado, desde luego, el progreso económico y el desarrollo del país en esos treinta años, teníamos un sentimiento generalizado de desigualdad y de impotencia ante un poder público cuyo ejercicio era extremadamente arbitrario. ¿Qué reclamábamos?: Igualdad, justicia social (que se cerraran las brechas entre gente muy rica y gente muy pobre, carente de oportunidades) y ante un México eminentemente rural, queríamos una justa distribución de la tierra. Asimismo, queríamos estabilidad, ante un país notoriamente fragmentado. Por eso era necesario que se lograra la construcción de un documento supremo que congregara los ideales de la Revolución.

Indudablemente existe un gran mérito en el constituyente de 1917. En términos estrictamente políticos, podríamos decir que la Revolución Mexicana inició como un movimiento para derrocar a Porfirio Díaz, pero terminó siendo una transformación total en el ámbito social, político, económico y jurídico.

En efecto, la Constitución Mexicana de 1917 es considerada la primera constitución social del mundo: establece límites al poder estatal, reconociéndole un marco de libertades a la persona y, al propio tiempo, regula los problemas relativos a la pobreza, la explotación, el despojo, el abuso de las potencias extranjeras, el reconocimiento de las personas más vulnerables.

Para ser considerada como la primera constitución social del mundo, basta revisar los artículos: tercero (el de la educación gratuita, laica y obligatoria), el 5 (la libertad laboral, profesional), el 27 (relativo a la propiedad de las tierras y aguas de la nación), el 28 (que establece la rectoría económica de la nación en beneficio del desarrollo del Estado y de los connacionales), el 123 que regula los derechos de los trabajadores. A la vista de ese marco regulatorio constitucional: educación, libertad de trabajo, defensa del campesino y de la clase trabajadora dieron cuenta de una encomiable visión de los creadores de nuestra Constitución de 1917. Lograron conciliar los principales intereses de una nación diversa, desgastada, desunida. Reflejaron una realidad palpable y una inspiración de país que creían realizable.

\section{Situación actual}

La Constitución de 1917 es de las más longevas de Latinoamérica y de algunas europeas (por ejemplo, la Alemana es de 1919; la de España es de 1978); tiene 136 artículos. De su promulgación a la fecha ha tenido más de 600 reformas. Muy pocos de sus artículos permanecen iguales. 114 
de esos 136 artículos tienen cambios sustanciales a los del texto original; además se ha engrosado de manera considerable. De acuerdo a un estudio del Instituto de Investigaciones Jurídicas de la Universidad Nacional Autónoma de México, tan solo de 1964 a 2015, la Constitución pasó de 27 mil a 66 mil palabras (más de 38 mil 400 palabras añadidas) ${ }^{2}$.

De este modo, (siguiendo el estudio referido) el 80\% de los artículos constitucionales originales han sido modificados un promedio de cinco veces cada uno y la Constitución ha sido modificada dos veces más que cualquier otra constitución democrática del mundo. Es de la más reformada del planeta. El promedio es que cada dos meses se produce un nuevo decreto que modifica o adiciona su texto. No ha existido un solo Presidente que no haya ejercido su facultad para enviar iniciativas de reforma al texto constitucional y logrado su cometido. Por ejemplo, Felipe Calderón logró colocar 110 modificaciones.

\section{Consistencia técnica-estructural}

Antes de abordar algunas transformaciones que ha tenido la Constitución Mexicana, es menester hacer algunas anotaciones. No es motivo de esta exposición entrar en detalles técnicos, ni tampoco profundizar en disquisiciones propias de la teoría constitucional. Sólo se hará una muy breve referencia sobre aquellos componentes o elementos que considero importantes para analizar la situación actual de nuestra Carta Magna.

\section{La supremacía constitucional como base y cúspide del orden jurídico}

Para que exista un Estado de Derecho, debe existir un orden jurídico. Al hacer referencia al orden jurídico, es menester ubicar un sistema de normas (leyes, reglamentos, decretos, etc.) que en su conjunto configuran una estructura unificada, congruente y coherente. Ahora, todo este sistema tiene una base técnica e ideológica que emana de la Constitución y todo el aparato normativo posterior tiene como soporte, orientación y límite dicha base. En otras palabras, nada puede ir más allá del texto constitucional. Por eso se le llama texto fundamental y a esa jerarquía máxima se le conoce como supremacía constitucional ${ }^{3}$.

\section{Defensa e inviolabilidad}

La supremacía constitucional también se ve reflejada en el último de sus preceptos (136). Dicho artículo regula que la Constitución nunca podrá perder su fuerza y vigor. ¿Qué pasaría si a consecuencia de una rebelión perdiera su observancia? ¿Qué pasaría si por algún trastorno público, se estableciera un gobierno contrario a los principios que ella regula?: Tan luego el pueblo recobrara su libertad, se establecería su observancia y con todo el orden jurídico, serían juzgados todos aquellos que hubieran actuado en la rebelión o cooperado con ella ${ }^{4}$.

\footnotetext{
${ }^{2}$ Ver, Instituto de Investigaciones Jurídicas e Instituto Iberoamericano de Derecho Constitucional, Hacia la reordenación y consolidación del texto de la Constitución Política de los Estados Unidos Mexicanos de 1917. "Estudio introductorio", [en línea] disponible en: http://www2.juridicas.unam.mx/constitucion-reordenada-consolida$\mathrm{da} /$ [consulta: 19/02/18, 17:59 horas].

3 Ver, Kelsen, Hans (2010), Compendio de Teoría General del Estado, Colofón, México, 2010; y Rosario-RodríGUEZ, Marcos Francisco del (2011), "La supremacía constitucional: naturaleza y alcances”, [en línea] disponible en: Díkaion, vol. 20, núm. 1, Universidad de La Sabana, Colombia.

${ }^{4}$ Ver, Valadés, Diego (2017), "La inviolabilidad de la Constitución de 1857 y el Congreso Constituyente de 1917", en: Cien ensayos para el centenario. Constitución Política de los Estados Unidos Mexicanos, tomo 2: Estudios
} 


\section{Posibilidad de su reforma}

Las normas, desde luego incluyendo las constitucionales, obedecen a una determinada dinámica social. Por ello deben ser susceptibles de modificarse, de adaptarse a las circunstancias cambiantes de la realidad.

En este sentido, hay dos tipos de constituciones: las flexibles, que tienen procesos ordinarios, sencillos para su modificación y las rígidas, que requieren de procesos más complejos para que se puedan reformar. La Constitución mexicana es rígida: para su reforma requiere de la aprobación de la Cámara de Diputados y de la de Senadores y también, por la mayoría de las legislaturas de los Estados y de la Ciudad de México.

\section{Estructura}

La Constitución tiene una sistemática, una técnica legislativa que se refleja en dos grandes apartados: la parte dogmática, que consagra los derechos fundamentales y la parte orgánica, que regula la forma de gobierno y la estructura del poder público.

\section{Algunas reformas}

Así como dijimos que para entender la Constitución de 1917 es necesario ubicarnos en el contexto de aquella época, también resulta conveniente hacer un esfuerzo para entender qué ha pasado en estos cien años en nuestro país y qué reformas se han derivado en la constitución. En otras palabras: para entender la historia de cien años en México, merece la pena visualizar las transformaciones a nuestra carta fundamental. Y a la inversa, para entender la constitución actual de la Constitución, habría que hacer un recorrido por la historia de México en los últimos cien años.

A continuación, se hará un breve recorrido por algunas reformas constitucionales significativas. Desde luego no son las únicas. Las que se describen representan sólo un esfuerzo de síntesis y ejemplificativo de un centenario de acontecimientos.

\section{a) Reformas que inciden en los basamentos revolucionarios}

La culminación del reparto agrario (artículo 27, en 1992)

\section{Antecedentes}

La reforma agraria mexicana ha sido un proceso complejo y prolongado. La reforma tuvo su origen en una revolución popular de gran envergadura y se desarrolló durante una guerra civil. El Plan de Ayala, propuesto por Emiliano Zapata y adoptado en 1911, exigía la devolución a los pueblos de las tierras que habían sido concentradas en las haciendas. En 1912 algunos jefes militares revolucionarios hicieron los primeros repartos de tierras. En 1915 las tres fuerzas re- 
volucionarias más importantes, el constitucionalismo, el villismo y el zapatismo, promulgaron las leyes agrarias.

Durante el largo período que se extiende de 1911 a 1992 se entregaron a los campesinos algo más de 100 millones de hectáreas de tierras, equivalentes a la mitad del territorio de México y a cerca de las dos terceras partes de la propiedad rústica total del país.

No obstante, el reparto institucional de las tierras no hace justicia al complejo papel de la reforma agraria a nivel de toda la nación. La estabilidad, gobernabilidad y desarrollo de México en el siglo XX se sustentaron en dicha reforma y permitieron la construcción de un país predominantemente urbano, industrial y dotado de un importante sector de servicios.

\section{Reforma}

La atención al pedido generalizado de tierras se convirtió en condición de la pacificación y del restablecimiento de un gobierno nacional hegemónico: la Constitución de 1917 incluyó el reparto de tierras en su artículo 27. Desde entonces, y con sucesivas adecuaciones hasta 1992, el reparto de tierras fue mandato constitucional y político del Estado mexicano. Dicho reparto sigue siendo prerrogativa del Estado si se concibe la reforma agraria como un concepto más amplio que la mera distribución de la propiedad. La reforma de 1992 incluyó un sistema integral de justicia agraria y de desarrollo sustentable de la producción agropecuaria, su industrialización y comercialización, considerándolas de interés público ${ }^{5}$.

Pero la reforma agraria aún dista mucho de lograr el bienestar sostenido de la población y las personas que aún viven una pobreza extrema.

Reconocimiento a las asociaciones religiosas de personalidad jurídica (artículos 3, 5, 24, 27 y 130; en 1992)

\section{Antecedentes}

En México el vínculo entre el Estado y la Iglesia católica históricamente ha sostenido relaciones complejas, hostiles, con encuentros y desencuentros. Su historia se refleja en la Constitución de 1917 que prácticamente redujo la religión en un asunto privado, liberando a la sociedad de ataduras religiosas y restringiendo la participación de la Iglesia en prácticamente todas las esferas de la vida social y política.

Hubo reacciones al respecto. La primera fue la rebelión cristera y el enfrentamiento abierto entre el Vaticano y la jerarquía eclesial nacional con el Estado mexicano.

A finales de la década de 1970, las relaciones Iglesia-Estado se fueron transformando y, en este marco, el protagonismo alcanzado por la institución eclesial durante la década de los ochenta le dotó de fuerza política. Fue legitimando su derecho para emitir opiniones en asuntos de orden político y su disposición de mantener relaciones cordiales con el gobierno mexicano.

En la década de 1990, estaba de su lado un entorno sociopolítico que manifestaba la crisis inminente del sistema político mexicano, al que el entonces nuevo presidente respondía con un

\footnotetext{
5 Ver, Mackinlay Grohmann, Horacio (1993), "Las reformas de 1992 a la legislación agraria. El fin de la Reforma Agraria mexicana y la privatización del ejido”, en: Polis, Investigación y Análisis Sociopolítico y Psicosocial, número 1993, Universidad Nacional Autónoma de México, México.
} 
proyecto de modernización económica neoliberal que exigía su correlato en los ámbitos político y social.

\section{Reforma}

En síntesis, consiste en otorgarle personalidad jurídica a las asociaciones religiosas, y otras modalidades, como por ejemplo que los ministros de culto religioso puedan votar ${ }^{6}$.

Reforma indígena (artículos 1, 2, 4, 18 y 115, en 2001)

\section{Antecedentes}

El primero de enero de 1994 se levantó en armas el Ejercito Zapatista de Liberación Nacional (EZLN) en el Estado de Chiapas. El gobierno mexicano respondió con sus fuerzas armadas, pero ante la presión social tanto nacional como internacional en contra de las acciones bélicas de Estado, el 12 de enero el entonces presidente Carlos Salinas de Gortari ordenó al ejército el cese al fuego. Fue hasta el 21 de febrero cuando comenzaron las conversaciones de paz en San Cristóbal de las Casas, Chiapas.

Una de las respuestas más afortunadas del Estado mexicano fue la creación de la Comisión de Concordia y Pacificación (COCOPA) en marzo de 1995, integrada por diputados y senadores federales de todos los partidos políticos, así como por integrantes del EZLN.

En febrero de 1996 se alcanzó el primer gran acuerdo firmado por el EZLN, avalado por la COCOPA y otras comisiones de pacificación. A este pacto se le llamó Acuerdos de San Andrés Larraízar. Tras una consulta popular, tuvieron una aceptación de 96\% de los pueblos indígenas.

En noviembre de 1996 se elabora por la COCOPA la iniciativa de reforma constitucional en materia de derechos y cultura indígena. Esta iniciativa buscó recoger la esencia de los Acuerdos de San Andrés Larraízar, firmados con anterioridad.

En diciembre de 2000, el recién Presidente Vicente Fox Quesada (que emanaba de un partido diferente al Revolucionario Institucional tras una hegemonía de setenta años), con el compromiso de campaña de lograr la paz en Chiapas, retomó la iniciativa de reforma constitucional elaborada años atrás por la COCOPA y la presentó al Senado de la República.

El mes siguiente la iniciativa de reforma constitucional fue aprobada primeramente por la Cámara de Senadores en su calidad de Cámara de Origen el 25 de abril, y aprobada por la Cámara de Diputados federal como Cámara Revisora el 28 de abril de 2001.

No obstante, después, el día 29 de abril, el EZLN desconoció formalmente la reforma constitucional sobre derechos y cultura indígenas, por no respetar los acuerdos de la COCOPA (ni los de San Andrés Larraízar) y rompió además el diálogo con el Gobierno mexicano.

Hay que tener en cuenta que desde la primera negociación con el gobierno se destacaron 34 demandas del EZLN, en las que además de temas de salud, vivienda, educación, saneamiento ambiental, electrificación, situación de la mujer, información independiente y libertad de los presos políticos y sociales, se plantearon tres asuntos de fondo: a) el respeto a los derechos, la

\footnotetext{
${ }^{6}$ Ver, González Schmal, Raúl (2008), “Régimen jurídico de las asociaciones religiosas en México”, en: Jurídica. Anuario del Departamento de Derecho de la Universidad Iberoamericana, número 38, México.
} 
cultura y las formas de auto-gobierno de los indígenas; b) el reparto de tierras, y c) la realización de elecciones libres y democráticas.

Huelga decir que las aspiraciones del EZLN nunca estuvieron encaminadas a vulnerar el Estado de derecho en México. Al contrario, básicamente solicitaban la inserción como pueblo no reconocido por el orden jurídico, y el cumplimiento de demandas emanadas de la heterogeneidad del pueblo mexicano.

\section{Reforma}

Fue un paso muy importante para avanzar en la construcción de una nueva relación entre el Estado, los pueblos indígenas y la sociedad.

Dicha reforma reconoce la composición pluricultural de la nación, se contempla la definición legal de pueblo y comunidad indígena, la libre determinación y autonomía y se señalan los derechos indígenas que pueden ejercerse en el marco de la Constitución y las leyes con respeto al pacto federal y la soberanía de los estados.

Asimismo, reconoce como normas los procedimientos y prácticas tradicionales de las comunidades indígenas; aquellas que desde siempre se han venido utilizando para su organización interna. El avance se observa en el reconocimiento constitucional de estas prácticas, en el hecho simbólico de sentirse escuchados y tomados en cuenta. Las nuevas normas jurídicas no impulsaron la generación de distintos comportamientos sociales. En sí, jugaron el papel de regularlos, de reconocer lo que estaba afuera de esa famosa pirámide positivista. Se reconoció la realidad para insertarla en el ordenamiento jurídico mexicano ${ }^{7}$.

\section{b) Reformas al poder público}

En este apartado se agregan aquellas reformas que han marcado una forma diferente de acceder, regular, configurar u orientar el poder público, así como la instauración de organismos nuevos.

\section{Reforma al poder legislativo}

La reforma político-electoral de 1977 reconoció a los partidos políticos como entidades de interés público; estableció la composición de la Cámara de Diputados en 400 diputados (30o de mayoría relativa y 100 de representación proporcional). Asimismo, perfiló un sistema de impugnación en materia electoral (creó el recurso de reclamación ante la SCJN por resoluciones del Colegio Electoral de la Cámara de Diputados; aunque esta disposición fue eliminada mediante la reforma política de 1986 que elevó a 200 los diputados plurinominales). Con esta reforma, además, se hizo extensivo el principio de representación proporcional hacia las legislaturas locales y los ayuntamientos. A la distancia, podemos observar en esta reforma la vuelta de llave que permitió la apertura del sistema electoral que habría de culminar con la transición de 2000.

Reforma al poder judicial. 1994. Transformación de la Suprema Corte de Justicia de la Nación en Tribunal Constitucional y creación del Consejo de la Judicatura Federal y los correlativos en

\footnotetext{
7 Ver, CARBONELL, Miguel (2002), “Constitución y derecho indígenas: introducción a la reforma constitucional del 14 de agosto de 2001”, en: Comentarios a la reforma constitucional en materia indígena, Miguel Carbonell y Karla Pérez Portilla (Coords.), UNAM, México; y Kurczyn Villalobos, Patricia (2002), "Reflexiones socio jurídicas a cerca de las reformas constitucionales 'en materia indígena”, en: Comentarios a la reforma constitucional en materia indígena, Miguel Carbonell y Karla Pérez Portilla (Coords.), UNAM, México.
} 
las entidades federativas (Artículos 21, 55, 73, 76, 79, 89, 93, 94, 95, 96, 97, 98, 99, 100, 101, 102, 103, 104, 105, 106, 107, 108, 110, 111, 116, 122 y 123).

\section{Reforma}

Se trata de una reforma judicial integral. Reduce el número de ministros de la Suprema Corte de Justicia y modifica el mecanismo de nombramiento de aquéllos. Crea el Consejo de la Judicatura Federal. Incorpora las figuras de controversia constitucional y acción de inconstitucionalidad. Con ello, se hizo de la corte un verdadero tribunal constitucional (en términos políticos, ello transformó al Judicial en un auténtico poder, contrapeso del Ejecutivo y Judicial y fiel de la balanza en los conflictos entre éstos y los órganos de gobierno de las entidades de gobierno y los municipios) $)^{8}$.

Posibilita que las resoluciones del Ministerio Público Federal sobre el no ejercicio de la acción penal puedan ser impugnadas. Somete a la ratificación del Senado el nombramiento de Procurador General de la República. Faculta al congreso para expedir leyes en materia de seguridad pública que establezcan las bases de coordinación entre la federación, el Distrito Federal, los estados y los municipios.

\section{Partidos y órganos electorales}

\section{Antecedentes}

La democracia mexicana ha estado ligada a uno de sus principales componentes -aunque desde luego no el único: hacer valer el sufragio efectivo, quién lo hace valer y cómo acceder a las posiciones electorales. Es decir: la regulación de los órganos electorales y de los partidos políticos. Al respecto, la Constitución ha tenido una prolija regulación que podríamos ubicar en las siguientes etapas.

\section{Reformas}

a) Reforma electoral de los 90. Incluyo aquí no una sino tres reformas constitucionales que, sin embargo, podrían verse como parte del "gran proyecto de reforma electoral" previa a la transición y que tuvo como objetivo fundar el sistema electoral mexicano.

La reforma de 1990 estableció las bases para la organización de las elecciones federales como una función estatal que se ejerce por los poderes Legislativo y Ejecutivo de la Unión, con la participación de los partidos políticos nacionales y de los ciudadanos. Precisó que la función electoral se realizaría a través de un organismo público dotado de personalidad jurídica y patrimonio propios (si bien es cierto que permaneció el sistema de auto-calificación de las elecciones por parte de las Cámaras de Diputados y Senadores).

b) La de 1993, por su parte, estableció de forma expresa que la ley secundaria regularía el financiamiento de los partidos políticos y sus campañas electorales. Facultó al órgano electoral para declarar

\footnotetext{
${ }^{8}$ Ver, CARPIZO, Jorge (1994), "Reformas constitucionales al Poder Judicial Federal y a la jurisdicción constitucional, del 31 de diciembre de 1994”, en: Boletín Mexicano de Derecho Comparado, número 83, UNAM, México, 1995 y Fix Fierro, Héctor, "Reformas y adiciones a la Constitución Federal en materia de administración de justicia", en: Anuario Jurídico, nueva serie, UNAM, México.
} 
la validez de las elecciones de diputados y senadores, suprimiendo el sistema de auto-calificación. Consagró al Tribunal Federal Electoral como la máxima autoridad jurisdiccional en materia electoral.

c) En 1996 se llevó a cabo la reforma integral en materia electoral y se legisló en los temas de prerrogativas y obligaciones de los ciudadanos mexicanos; atribuciones e integración del Instituto Federal Electoral; financiamiento de los partidos políticos; composición de las cámaras del Congreso de la Unión; justicia electoral; sistema de responsabilidades; y correspondencia de las legislaciones electorales locales.

Bien vale la pena destacar que, en el tema de prerrogativas y financiamiento público de los partidos políticos, 11 años después de aquella reforma integral (el 13 de noviembre de 2007), se aprobó una nueva reforma que redujo el financiamiento público para gasto en campañas electorales y ajustó los límites para el financiamiento privado. Hoy presenciamos uno de los debates más agrios, descuidados y preocupantes de nuestra democracia precisamente en materia de financiamiento e integración del Congreso de la Unión ${ }^{9}$.

d) 2014. Última reforma político-electoral (artículos 26, 28, 29, 35, 41, 54, 55, 59, 65, 69, 73, 74, 76, 78, $82,83,84,89,90,93,95,99,102,105,107,110,111,115,116,119$ y 122$)$.

Se crea el Instituto Nacional Electoral; se incorpora la reelección consecutiva de senadores y diputados federales, diputados locales, presidentes municipales, regidores y síndicos ${ }^{10}$.

\section{Creación de los organismos públicos constitucionales (artículo 102, en 1992)}

\section{Antecedentes}

En 1990 fue creada la Comisión Nacional de los Derechos Humanos, como un órgano desconcentrado de la Secretaría de Gobernación, con la encomienda de proponer y vigilar el cumplimiento de la política nacional en materia de respeto y defensa de los Derechos Humanos. Al paso del tiempo, surgió una crítica social que ponía en entredicho su libre actuar y proceder, en razón de la dependencia administrativa directa del Poder Ejecutivo Federal.

Por ello, en 1992 se llevó a cabo una reforma constitucional por medio de la cual la Comisión Nacional se transformó en un organismo descentralizado, con personalidad jurídica y patrimonio propios, responsabilizado de la protección, observancia, promoción, estudio y divulgación de los Derechos Humanos amparados por el orden jurídico mexicano.

\footnotetext{
9 Para analizar las reformas constitucionales de 1993 y 1996 en esta materia Ver, Woldenberg, José et ál. (200o), La mecánica del cambio político en México. Elecciones, partidos y reformas, Ediciones Cal y Arena, México.

${ }^{10}$ Ver, Alarcón Olguín, Víctor (2016), “Reformas político-electorales 2012-2014 y régimen de gobierno”, en: Temas selectos de Derecho electoral, número 51, Tribunal Electoral del Poder Judicial de la Federación, México.
} 


\section{Reformas}

Se crean los organismos públicos constitucionales autónomos fuera de la órbita y del control de los poderes constituidos; destacando los organismos no jurisdiccionales de protección de derechos humanos ${ }^{11}$.

A partir de esa fecha se han ido incorporando una serie de órganos constitucionales autónomos. Estas instancias cobran gran relevancia en los Estados Constitucionales Democráticos ya que aparecen en el marco de procesos de transición democrática y de construcción del Estado Constitucional de Derecho.

\section{Incorporación de la responsabilidad patrimonial del estado (artículo 113, en2002)}

\section{Antecedentes}

En nuestro país no contábamos con un auténtico sistema de responsabilidad patrimonial del Estado, lo que implicaba un rezago en el fortalecimiento del principio de seguridad jurídica y del Estado de Derecho. Hasta el momento de esta reforma, la responsabilidad del Estado estaba apoyada en los principios civiles de la culpa, dominando la responsabilidad de exigibilidad subsidiaria como regla general, además de la ausencia de un procedimiento eficaz para que los particulares estuviesen en posibilidad de impetrar reparaciones. Existían grandes dificultades técnicas que debía sortear el particular cuando intentaba deducir una acción resarcitoria contra el Estado.

Las dificultades de la aplicación de la teoría de la culpa en el deslindamiento de la responsabilidad patrimonial del Estado eran las siguientes: a) Imposibilidad de identificar a los autores materiales cuando se trata de los daños impersonales o anónimos; b) Los obstáculos para demostrar la ilicitud en el proceder de los servidores públicos y la insolvencia en que se hallen para enderezar la acción contra el Estado, cuyas secuelas se notan en procedimientos prolongados y complicados; c) Limitación estructural de la teoría de la culpa en los casos de la producción de daños derivados del actuar lícito o normal de la Administración Pública, y d) La teoría de la culpa explicable en las personas físicas resulta inaplicable para el Estado al ser una persona jurídica o moral.

\section{Reforma}

Esta reforma constituye un trascendente avance de nuestro orden jurídico ya que dota a los administrados de un nuevo medio de defensa frente a la administración pública, permitiéndoles la indemnización en caso de responsabilidad por parte del Estado. Crea pues, un sistema de responsabilidad directa y objetiva del Estado ${ }^{12}$.

\section{a) Rectoría del estado en la economía y el desarrollo nacional}

La reforma derivada de la crisis del 82 (artículos 25, 26, 27, 28 y 73)

\footnotetext{
${ }^{11}$ Ver, Fix Fierro, Héctor (1993), "La reforma al artículo 102 de la Constitución”, en: Boletín Mexicano de Derecho Comparado, número 77, México.

${ }^{12}$ Ver, Castro Estrada, Álvaro (1997), "La responsabilidad patrimonial del Estado en México. Fundamento constitucional y legislativo, en: Jurídica. Anuario del Departamento de Derecho de la Universidad Iberoamericana, número 27, México.
} 


\section{Antecedentes}

En 1982 se dio una gran crisis económica en México. Devaluación monetaria, inflación, deuda externa, estancamiento económico, desempleo, expropiación y nacionalización de la banca, en general un ambiente de desconfianza e incertidumbre. En conclusión, existía una ingobernabilidad económica.

\section{Reforma}

El Estado tiene la responsabilidad de organizar y conducir el desarrollo nacional. La economía en México es mixta, intervienen el sector público, privado y social. Se institucionaliza la planeación estatal.

11. 2013. Reforma energética (artículos 25, 27 y 28)

\section{Antecedentes}

El modelo energético actual está agotado y mientras tanto la industria petrolera mundial encuentra alternativas para incrementar sus utilidades. La mayor parte de las corporaciones reducen al máximo costos, incrementan la eficiencia operativa, flexibilizan contrataciones, tercerizan y establecen alianzas estratégicas, posicionan su marca, establecen planes de internacionalización, bursatilizan y emiten deuda para potencializar el capital social de sus unidades económicas. Dichas prácticas, son realizadas en la actualidad por empresas estatizadas o privadas, con independencia del sistema jurídico de pertenencia. La problemática principal se localiza en dos ejes de la industria: la producción de crudo y la refinación, aspectos que requieren incrementarse al máximo posible para obtener una mayor renta petrolera nacional y por otro lado, mitigar la importación de gasolinas; sobre todo considerando que de 2004 a la fecha, la producción de petróleo crudo ha disminuido un $37.2 \%$, al tiempo que la falta de capacidad refinadora orilla a la importación de la gasolina para suministrar el consumo nacional, lo cual repercute directamente en los altos precios del combustible. A pesar de la importancia por atender dichos aspectos, en la última década persistió un temor casi inexplicable por modificar el texto constitucional.

Es de destacar que, en el año 2008, el Ejecutivo Federal eludió la reforma constitucional y dirigió sus esfuerzos en las reformas a las leyes secundarias. Sin embargo, resultó insuficiente para generar el crecimiento económico que demandan los mexicanos, revelándose de nueva cuenta la necesidad por modificar el modelo energético de la Nación.

\section{Reforma}

Se permite al Estado la celebración de contratos con particulares para la exploración y extracción del petróleo y otros hidrocarburos, así como para la transmisión y distribución de energía eléctrica ${ }^{13}$.

\footnotetext{
${ }^{13}$ Ver, CÁrdenas Gracia, Jaime Fernando (2015), "Variables jurídico-constitucionales de la reforma energética", en: Estado constitucional, derechos humanos, justicia y vida universitaria. Estudios en homenaje a Jorge Carpizo. Estado constitucional, tomo IV, volumen I, (Carbonell, Miguel et ál.), UNAM, México.
} 


\section{d) Reformas en materia de derechos humanos}

2011. Reforma sustantiva (artículos 1, 3, 11, 15, 18, 29,33, 89,97, 102 y 105)

\section{Antecedentes}

Esta reforma llega en un momento especialmente delicado, cuando la situación de los derechos humanos en el país se ha degradado considerablemente en el contexto de una exacerbada violencia y de una actuación desbocada e ilegal de un sector de las fuerzas armadas.

Llega también cuando México acumula ya seis sentencias condenatorias de la Corte Interamericana de Derechos Humanos, que han verificado en el plano internacional lo que ya se sabía: el Estado mexicano presenta profundas deficiencias en la tutela de los derechos.

\section{Reforma}

Es una de las reformas constitucionales más importantes en la historia de México, ya que obedece a las necesidades y exigencias actuales relacionadas con una mejor protección y defensa de los derechos humanos ${ }^{14}$.

Los cambios más trascendentales son los siguientes:

1) La sustitución del término garantías individuales por el de derechos humanos. Esta adecuación la vamos a encontrar prácticamente a lo largo de todo el texto constitucional y obedece a que el termino garantía individual no es compatible con la doctrina contemporánea.

2) El reconocimiento de los derechos humanos contenidos en tratados internacionales en los que México sea parte, es decir, aparece el bloque de constitucionalidad.

3) Se recoge la figura de la "interpretación conforme", al señalarse que todas las normas relativas a derechos humanos (del rango jerárquico que sea) se deberán interpretar a la luz de la propia Constitución y de los tratados internacionales. Esto implica la creación de una especie de bloque de constitucionalidad (integrada no solamente por la carta magna, sino también por los tratados internacionales), a la luz del cual se deberá interpretar el conjunto del ordenamiento jurídico mexicano.

4) Se incorpora el principio de interpretación pro personae, muy conocido en el derecho internacional de los derechos humanos y en la práctica de los tribunales internacionales encargados de la protección y tutela de los mismos derechos. Este principio supone que, cuando existan distintas interpretaciones posibles de una norma jurídica, se deberá elegir aquella que más proteja al titular de un derecho humano. Y también significa que, cuando en un caso concreto se puedan aplicar dos o más normas jurídicas, el intérprete debe elegir aquella que (igualmente) proteja de mejor manera a los titulares de un derecho humano.

5) La obligación del Estado Mexicano de respetar, proteger y garantizar los derechos humanos de conformidad a los principios de universalidad, interdependencia, indivisibilidad y progresividad.

\footnotetext{
14 Para conocer la postura del autor en torno a la reforma constitucional: Ver, Guerrero Agripino, Luis Felipe (2014), La delincuencia organizada, algunos aspectos penales, criminológicos y político criminales, segunda edición, UBIJUS, México, pp. 51-54 y Guerrero Agripino, Luis Felipe, Astraín Bañuelos, Leandro Eduardo (2014), "El arraigo y su control de convencionalidad en México", en: Derechos humanos, actualidad y desafío III, Fontamara.
} 
6) Una de las finalidades de la educación que imparta el Estado mexicano deberá ser el respeto a los derechos humanos.

7) Prohibición de celebrar tratados internacionales que menoscaben los derechos humanos reconocidos por la constitución y los tratados internacionales de los que el Estado Mexicano sea parte.

8) Garantía de audiencia para extranjeros. La reforma constitucional reviste a los extranjeros del derecho a ser oídos y vencidos en juicio cuando incurran en alguna causal legal que determine su expulsión del país. Lo que quiere decir que ahora el régimen de extranjeros en México queda robustecido.

9) Transferencia de la facultad de investigación en materia de violaciones graves a derechos humanos por parte de la Suprema Corte de Justicia de la Nación (SCJN) a la Comisión Nacional de los Derechos Humanos (CNDH). Esta transferencia se da a causa de que la $\mathrm{CNDH}$ es un órgano ex profeso para la protección y defensa de los derechos humanos, con lo que deja a la SCJN exclusivamente protección y defensa en el ámbito meramente jurisdiccional.

\section{Reforma integral del juicio de amparo (artículos 94, 103, 104 y 107, en 2011)}

\section{Antecedentes}

El juicio de amparo se había vuelto anacrónico y excesivamente formal, ya hacía varias décadas que tanto la academia como los jueces propugnaban por un cambio acorde a los criterios internacionales, capaz de hacer frente a las exigencias de la justicia de la sociedad mexicana.

\section{Reforma}

Es una reforma constitucional muy ambiciosa que debe ser entendida en relación con la reforma constitucional en materia de derechos humanos que se publicó unos días más tarde en el Diario Oficial de la Federación, el 10 de junio de 2011, en tanto que ambos cambios constitucionales sitúan a los tratados en materia de derechos humanos en una posición preponderante en el ordenamiento y promueven la maximización de los derechos humanos en la interpretación y aplicación para su debida garantía. Entre las aportaciones más destacables de la reforma constitucional en materia de amparo podemos mencionar las siguientes: 1) se determina que el juicio de amparo es procedente por violaciones a normas contenidas en los tratados sobre derechos humanos y no sólo por violaciones a los derechos reconocidos en la constitución; 2) en algunos supuestos se elimina el principio decimonónico — cláusula Otero- de la relatividad de las sentencias de amparo para señalar que algunas resoluciones de amparo pueden tener efectos erga omnes; 3 ) se proponen nuevos criterios para que la jurisprudencia tenga carácter obligatorio; 4) se incorpora el interés legítimo en cierto tipo de amparos; 5) amplía a los sujetos legitimados para promover contradicciones de tesis; 6) crea los plenos de circuito para resolver los conflictos suscitados con motivo de las contradicciones de tesis; 7) Introduce constitucionalmente la figura del amparo adhesivo, y 8) limita los amparos para efectos; entre otras trascendentes innovaciones ${ }^{15}$.

\footnotetext{
${ }^{15}$ Ver, CÁrdenAs, Jaime (2013), "La nueva Ley de Amparo”, en: Cuestiones constitucionales, Revista Mexicana de Derecho Constitucional, número 29, julio-diciembre, México.
} 


\section{e) Régimen anticorrupción y transparencia (2015)}

\section{Antecedentes}

Desde antaño, un reclamo de la sociedad mexicana ha sido el abuso del poder por parte de quienes ejercen el poder público, afectando la base financiera del país y su andamiaje democrático.

En diversas etapas del desarrollo político del país hemos encontrado programas como "La Renovación Moral", o expresiones como "cero tolerancia a la corrupción". De esa manera se puede apreciar un clima importante de desconfianza hacia la clase política y a las instituciones.

Esto ha dado lugar a una reforma de singular trascendencia en el sistema constitucional y legal mexicano. Se trata prácticamente de otro régimen de excepción en el tratamiento de la corrupción. A esta regulación también corresponde la relativa a la transparencia y rendición de cuentas.

\section{Reformas}

Algunas características de este régimen son de índole legal, estructural y, desde luego jurídico. Sus bondades se dibujan sobre todo en la generación de buenas prácticas, autonomía de órganos, la tendencia a la ciudadanización y la apertura del concepto: no sólo a los servidores públicos, sino también a particulares ${ }^{16}$.

Una singularidad de este sistema es el rigor punitivo, en dos velocidades: la administrativa y la penal. Nos encontramos con una cuestión insoslayable: establecer los límites al régimen sancionador administrativo, lo cual no es un asunto menor. El tiempo lo dirá.

\section{f) Reforma al sistema penal}

\section{Antecedentes}

Uno de los ámbitos en donde más se pone en evidencia la relación entre el poder público con los gobernados se encuentra en el sistema penal. Se encuentra aquí, porque estamos hablando del máximo rigor punitivo del que dispone el Estado: afectar uno de los bienes jurídicos más importantes de la persona: la libertad en aras de salvaguardar otros bienes jurídicos.

Para los efectos de esta exposición, cuando hablamos del sistema penal, nos estamos refiriendo al qué, es decir, aquellas esferas en las que el Estado debe implementar su máximo rigor punitivo (el Derecho penal) y bajo ese análisis, qué bienes jurídicos debe considerar que deben tener este nivel de protección. También nos estamos refiriendo al cómo. Es decir, bajo qué modalidades, reglas, el Estado determina que una persona en lo particular ha infringido la ley penal y por lo tanto amerita sus consecuencias (proceso penal). También tiene que ver con la

\footnotetext{
${ }^{16}$ En materia de rendición de cuentas y combate a la corrupción: Ver, KurCzyn Villalobos, Patricia, "Rendición de cuentas y combate a la corrupción”, en: ¿Cómo combatir la corrupción?, SAlazar Ugarte, Pedro et ál. (Coord. 2017), UNAM, México. En lo que respecta al régimen de transparencia, Ver: López Ayllón, Sergio (2017), "La transparencia gubernamental", en: Cien ensayos para el centenario. Constitución Política de los Estados Unidos Mexicanos, tomo 2: Estudios jurídicos, Gerardo Esquivel (Coord.), UNAM, México.
} 
forma e intensidad con la cual aplicará sus consecuencias jurídicas (sobre todo la pena de prisión), así como delimitar cuál es la finalidad de aplicar esas consecuencias.

Además, estamos hablando del tratamiento igual o diferenciado en relación con las personas que pueden ser sujetos de la responsabilidad penal (niños o adolescentes). También tiene que ver con la protección de quienes recienten el comportamiento delictivo (las víctimas).

Aunado a la anterior delimitación conceptual, merece la pena hacernos la siguiente pregunta: ¿Ha variado la criminalidad de ahora, en comparación con la de 1917? Acompañando a esa interrogante, hay que agregar otra: ¿los límites al poder del Estado en esta materia deben ser los mismos que los de 1917 ?

\section{Reformas}

1. En materia procesal. De inicio, a mediados de los noventa, se propiciaron reformas sobre el estándar probatorio y baremos sustantivos para detener y someter a proceso a la persona. Particularmente me refiero a los requisitos para dictar una orden de aprehensión o lo que se conocía como auto de formal prisión ${ }^{17}$.

2. En el año 2000, se agregó un apartado al artículo 20 a fin de incorporar derechos de la víctima, en virtud de que, hasta ese momento, sólo estaban los del imputado ${ }^{18}$.

3. Se hizo un cambio sustancial en el régimen penitenciario: el texto original regulaba, como fin de la pena de prisión, la readaptación social. Y como medios para facilitarla era: la educación, el trabajo y la capacitación para el mismo. Derivado de una reforma en 2011, se sustituyó el fin de la pena: reinserción por readaptación y se establecieron como fines para ello: el respeto a los derechos humanos, el trabajo, la capacitación para el mismo, la educación, la salud y el deporte.

4. En el año 2005 se estableció un sistema integral de justicia penal para niños y adolescentes, dado que anteriormente sólo se les consideraba inimputables. Esquema diferenciado $12-18$ años $^{19}$.

5. En el año 2008 sucede una gran reforma:

6. Se cambia el sistema procesal penal. Se pasa de uno mixto a uno de corte acusatorio, con todo lo que ello implica: oralidad, autocomposición, publicidad, limitación de la prisión preventiva, bajo la base preponderante del respeto al principio de presunción de inocencia.

También se regula un régimen de excepción en contra de un sector de la criminalidad: la delincuencia organizada. Para esta forma de expresión delictiva se establecen medidas como el arraigo, intervención de comunicaciones privadas, encarcelamiento en prisiones de máxima seguridad.

\footnotetext{
${ }^{17}$ Ver, Guerrero Agripino, Luis Felipe (2017), Fundamentos de la dogmática jurídica penal, una perspectiva desde los derechos humanos, CNDH, México.

${ }^{18}$ Ver, Guerrero Agripino, Luis Felipe (2012), “Tendencias en torno a la protección de la víctima en el sistema penal mexicano", en: Revista General de Derecho Penal Iustel, número 18, España.

${ }^{19}$ Ver, Guerrero Agripino, Luis Felipe (2011), "Dogmática penal y proceso penal. Encuentros, desencuentros y tensiones en el sistema mexicano", en: Revista General de Derecho Penal Iustel, número 16, España.
} 


\section{Conclusiones}

Derivado del análisis anterior, nuestras conclusiones las oriento en los siguientes rubros:

\section{El abuso:}

Es una de las constituciones más reformadas. El problema está en que muchas de esas reformas obedecen a situaciones coyunturales, emergentes, reactivas o simplemente porque se pretende dar la idea de que se está haciendo algo.

De la tendencia anterior, se derivan otros problemas. Por ejemplo, el abuso de derechos programáticos, eminentemente aspiracionales: por ejemplo, el derecho al agua, a una vivienda digna, etc. El inconveniente es que se convierten en letra muerta o, lo peor es que se generan falsas expectativas en la ciudadanía. Otro problema es la saturación de preceptos que deberían formar parte de leyes o reglamentos y no de la carta fundamental.

La tendencia a modificar la constitución para que ésta, con dicha modificación, constituya prácticamente el programa de gobierno en turno. Dicha tendencia propicia confusiones y falta de continuidad.

\section{El desconocimiento y falta de legitimación}

De acuerdo con la Tercera Encuesta Nacional de Cultura Constitucional realizada en 2016, por el Instituto de Investigaciones Jurídicas de la UNAM, el 60\% de las personas respondió que nuestra Constitución ya no responde a las necesidades del país. Asimismo, el 38.1\% señala que debería convocarse a un nuevo constituyente, pese que el 90\% de los encuestados reconoció conocer poco o nada de este documento normativo.

\section{Insuficiencias e inconsistencias internas:}

El ejemplo claro se encuentra en las dicotomías entre el artículo primero con otro tipo de regulaciones. Un ejemplo elocuente es el arraigo.

\section{El reto:}

Uno de los principales retos es encontrar el verdadero sentido a los alcances del artículo primero, en cuanto al control de convencionalidad. Esto conlleva la necesidad de generar una verdadera dogmática de los Derechos humanos a fin de propiciar su aplicación más acorde y no correr el riesgo de hacerlos nugatorios o al darle un sentido o connotación distorsionado se lleguen a violar derechos humanos con la bandera de los derechos humanos.

\section{VII. Última consideración}

En una época de cambios vertiginosos en el mundo y particularmente en México, resulta necesario retomar la esencia ideológica, política, histórica y jurídica de la Constitución Mexicana y de su ordenamiento jurídico general. Me resisto a pensar en otro constituyente, pues el riesgo es alto, dado que por el momento no se aprecia un nivel de estabilidad y madurez política. Por eso 
lo que hay que hacer es cuidarla, preservarla y protegerla. Si no lo hacemos, de nueva cuenta, terminaremos envueltos en el laberinto de nuestra soledad.

\section{Bibliografía}

CARbonell, Miguel (2002), “Constitución y derecho indígenas: introducción a la reforma constitucional del 14 de agosto de 2001", en: Comentarios a la reforma constitucional en materia indígena, Miguel Carbonell y Karla Pérez Portilla (Coords.), UNAM, México.

CÁrdenas Gracía, Jaime Fernando (2015), "Variables jurídico-constitucionales de la reforma energética”, en: Estado constitucional, derechos humanos, justicia y vida universitaria. Estudios en homenaje a Jorge Carpizo. Estado constitucional, tomo IV, volumen I, (Carbonell, Miguel et ál.), UNAM, México.

CÁrdenas, Jaime (2013), “La nueva Ley de Amparo”, en: Cuestiones constitucionales, Revista Mexicana de Derecho Constitucional, número 29, julio-diciembre, México.

CARPIZO, Jorge (1995), "Reformas constitucionales al Poder Judicial Federal y a la jurisdicción constitucional, del 31 de diciembre de 1994", en: Boletín Mexicano de Derecho Comparado, número 83, UNAM, México.

Castro Estrada, Álvaro (1997), "La responsabilidad patrimonial del Estado en México. Fundamento constitucional y legislativo", en: Jurídica. Anuario del Departamento de Derecho de la Universidad Iberoamericana, número 27, México.

Fernández Ruiz, Jorge (2013), "El constitucionalismo en el primer siglo del México independiente", en: Constitucionalismo, dos siglos de su nacimiento en América Latina, César Astudillo y Jorge Carpizo (Coords.), UNAM, México.

Fix Fierro, Héctor (1993), "La reforma al artículo 102 de la Constitución”, en: Boletín Mexicano de Derecho Comparado, número 77, México.

(1994), "Reformas y adiciones a la Constitución Federal en materia de administración de justicia”, en: Anuario Jurídico, nueva serie, UNAM, México.

GonzÁlez Schmal, Raúl (2008), "Régimen jurídico de las asociaciones religiosas en México", en: Jurídica. Anuario del Departamento de Derecho de la Universidad Iberoamericana, número 38, México.

Guerrero Agripino, Luis Felipe (2011), “Dogmática penal y proceso penal. Encuentros, desencuentros y tensiones en el sistema mexicano", en: Revista General de Derecho Penal Iustel, número 16, España.

(2012), “Tendencias en torno a la protección de la víctima en el sistema penal mexicano”, en: Revista General de Derecho Penal Iustel, número 18, España.

(2017), Fundamentos de la dogmática jurídica penal, una perspectiva desde los derechos humanos, CNDH, México. 
(2014), La delincuencia organizada, algunos aspectos penales, criminológicos y político criminales, segunda edición, UBIJUS, México.

Guerrero Agripino, Luis Felipe, Astraín Bañuelos, Leandro Eduardo (2014), "El arraigo y su control de convencionalidad en México", en: Derechos humanos, actualidad y desafío III, Fontamara.

Instituto de Investigaciones Jurídicas e Instituto Iberoamericano de Derecho Constitucional, Hacia la reordenación y consolidación del texto de la Constitución Política de los Estados Unidos Mexicanos de 1917. "Estudio introductorio". [En línea] disponible en: http:// www2.juridicas.unam.mx/constitucion-reordenada-consolidada/ [consulta: 19/02/18, 17:59 horas].

Kelsen, Hans (2010), Compendio de Teoría General del Estado, Colofón, México.

Kurczyn Villalobos, Patricia (2002), "Reflexiones socio jurídicas a cerca de las reformas constitucionales 'en materia indígena"', en: Comentarios a la reforma constitucional en materia indígena, Miguel Carbonell y Karla Pérez Portilla (Coords.), UNAM, México.

(2017), "Rendición de cuentas y combate a la corrupción”, en: ¿Cómo combatir la corrupción?, Salazar Ugarte, Pedro (et ál.) (Coord.), UNAM, México.

López Ayllón, Sergio (2017), "La transparencia gubernamental”, en: Cien ensayos para el centenario. Constitución Política de los Estados Unidos Mexicanos, tomo 2: Estudios jurídicos, Gerardo Esquivel (Coord.), UNAM, México.

Mackinlay Grohmann, Horacio (1993), "Las reformas de 1992 a la legislación agraria. El fin de la Reforma Agraria mexicana y la privatización del ejido", en: Polis, Investigación y Análisis Sociopolítico y Psicosocial, número 1993, Universidad Nacional Autónoma de México, México.

Rosario-Rodríguez, Marcos Francisco del (2011), "La supremacía constitucional: naturaleza y alcances”, en: Díkaion, vol. 20, núm. 1, Universidad de La Sabana, Colombia.

VAladÉs, Diego (2017), "La inviolabilidad de la Constitución de 1857 y el Congreso Constituyente de 1917", en: Cien ensayos para el centenario. Constitución Política de los Estados Unidos Mexicanos, tomo 2: Estudios jurídicos, Gerardo Esquivel (Coord.), UNAM, México, 2017.

Alarcón Olguín, Víctor (2016), "Reformas político-electorales 2012-2014 y régimen de gobierno", en: Temas selectos de Derecho electoral, número 51, Tribunal Electoral del Poder Judicial de la Federación, México.

Woldenberg, José et ál. (2000), La mecánica del cambio político en México. Elecciones, partidos y reformas, Ediciones Cal y Arena, México. 
